\title{
Estimation of Population Size Using Sample Maximum
}

\author{
Jaya Limbore ${ }^{1}$, Rajendra Gurao ${ }^{2}$ \\ ${ }^{1}$ Research Scholar, JJT University, Rajasthan, India \\ ${ }^{2}$ Brihan Maharashtra College, Pune, India
}

\begin{abstract}
Most of statistical inference is developed around the sample mean. Very little attention is paid to other sample quantities like the sample maximum. However, there are many situations where the interest is in the maximum rather than in the average. In sports, for example, the winner is not decided by the average, but by the best performance. Investment decisions are not governed by the average returns, but the maximum possible returns. This paper attempts to identify statistical inference that can be drawn from the sample maximum.
\end{abstract}

Keywords: Sample Maximum, Expected Value, Order Statistics, Simple Random Sampling, Maximum Likelihood Estimator

\section{Introduction}

The sample maximum is not considered to be of much consequence in most of the statistical literature. In many situations, however, the sample maximum provides the optimal solution. In finite population sampling, when the population size is not known, the sample maximum provides an estimate of the population size. The sample maximum is the maximum likelihood estimate of the population parameter $\theta$ for the uniform distribution on $[0, \theta], \theta>0$. The sample maximum estimates an upper quantile when the sample space is not bounded above. These and some other properties of the sample maximum are investigated in this paper. The purpose of this paper is to put together results related to the sample maximum to highlight the utility of the largest value in the sample.

In different situations, the sample maximum may be identified or specified in different ways. An outlier would be the sample extreme (that is, maximum or minimum), even though the sample maximum (or minimum) need not be an outlier. In some cases, the sample maxima, observed sequentially over a period of time, are called record values. In case of record values, the interest is in the record value as well as the expected time to the next record value. The famous German Tank problem is an example of estimating the population size (or, equivalently, the population maximum) using the sample maximum. Population ecologists use the sample maximum indirectly in their innovative method of capture-mark-recapture method for estimating the population size.

\section{The German Tank Problem}

The German tank problem involves estimating the maximum of a discrete uniform distribution using a simple random sample drawn without replacement. The name of the method is due to its application in the Second World War when it was used for estimation of the number of German tanks. Results of estimating the population maximum on the basis of single samples can be diverse. On the other hand, estimation based on multiple samples is simple but not obvious.
Let $\mathrm{N}$ denote the population size and $\mathrm{k}$ be the sample size. Let $X_{1}, X_{2}, \ldots, X_{n}$ be the sample and let $X_{(1)}, X_{(2)}, \ldots, X_{(k)}$ be the order statistics, so that the sample maximum is denoted by $X_{(\mathrm{k})}$. The probability mass function of $X_{(\mathrm{k})}$ is given by

$$
\mathrm{P}\left[\mathrm{X}_{(\mathrm{k})}=\mathrm{m}\right]=\frac{\left(\begin{array}{c}
\mathrm{m}-1 \\
\mathrm{k}-1
\end{array}\right)}{\left(\begin{array}{l}
\mathrm{N} \\
\mathrm{k}
\end{array}\right)}, \mathrm{m}=\mathrm{k}, \mathrm{k}+1, \ldots, \mathrm{N} .
$$

This gives, $E\left[X_{(k)}\right]=k \frac{N+1}{k+1}$.

When $X_{(\mathrm{k})}$ is known and the population size $\mathrm{N}$ is unknown, an estimate of $\mathrm{N}$ is given by

$$
\widehat{\mathrm{N}}=\left(1+\frac{1}{\mathrm{k}}\right) \mathrm{X}_{(\mathrm{k})}-1 \text {. }
$$

During the Second World War, the Allied intelligence agencies estimated that the Germans were producing around 1400 tanks per month during June 1940 to September 1942. The formula derived above gave an estimate of 256 per month. After the war, the figures from the ministry showed the actual number to the 255 per month.

In some versions of the German tank problem, however, the population size $\mathrm{N}$ is treated as a random variable and its probabilistic behaviour is investigated when the sample size $\mathrm{k}$ and the sample maximum $\mathrm{X}_{(\mathrm{k})}=\mathrm{m}$ are known.

In this setup, $P\left[N=n \mid k, X_{(k)}=m\right]=\frac{k-1}{k} \frac{\left(\begin{array}{c}m-1 \\ k-1\end{array}\right)}{\left(\begin{array}{l}n \\ k\end{array}\right)}$, for $n \geq m$.

The probability that the population size $\mathrm{N}$ exceeds $\mathrm{n}$ is then given by

$$
\begin{gathered}
\mathrm{P}[\mathrm{N}>\mathrm{n} \mid \mathrm{k}, \mathrm{m}]=\frac{\left(\begin{array}{l}
\mathrm{m}-1 \\
\mathrm{k}-1
\end{array}\right)}{\left(\begin{array}{c}
\mathrm{n} \\
\mathrm{k}-1
\end{array}\right)} \text { if } \mathrm{n} \geq \mathrm{m} . \\
=1 \text { if } \mathrm{n}<\mathrm{m} .
\end{gathered}
$$

The basic result in deriving the moments of $\mathrm{N}$ is the following identity for binomial coefficients.

$$
\sum_{\mathrm{n}=\mathrm{m}}^{\infty} \frac{1}{\left(\begin{array}{c}
\mathrm{n} \\
\mathrm{k}
\end{array}\right)}=\frac{\mathrm{k}}{\mathrm{k}-1} \frac{1}{\left(\begin{array}{c}
\mathrm{m}-1 \\
\mathrm{k}-1
\end{array}\right)} \text {. }
$$

Using this identity, the expected value of $\mathrm{N}$ given $\mathrm{k}$ and $\mathrm{m}$ is $\mathrm{E}[\mathrm{N} \mid \mathrm{k}, \mathrm{m}]=(\mathrm{m}-1) \frac{\mathrm{k}-1}{\mathrm{k}-2}$, for $\mathrm{k} \geq 3$.

The two results derived above show how the statistical setup for the same situation can affect the result. 


\section{International Journal of Science and Research (IJSR) \\ ISSN (Online): 2319-7064}

Index Copernicus Value (2013): 6.14 | Impact Factor (2015): 6.391

\section{Capture-Mark-Recapture Method}

Many ecological studies have an interest in estimating the abundance of a particular population. This is true for population ecology as well as community ecology. One way to estimate the population size is to begin by capturing some individual from the population and marking them before releasing them back in their natural condition. Another sample is subsequently selected to find out how many of them are marked. This simple principle was first used for estimating human population of London in1962 by John Graunt. The Danish fisheries biologists C.G.J. Petersen carried out the first ecological use of mark-and-recapture method in 1896 (see Ricker, 1975). The initial purpose in tagging of fish was to study movements and migration of individuals, but it was soon realized that tagging can also be used for estimating population size. Lincoln (1930) estimated the abundance of ducks using the mark-recapture method. Jackson (1933) applied mark-recapture method to insect population for the first time.

The strength of mark-and-recapture techniques is in the additional information on birth, death, and movement rates beyond the basic information on abundance. The weakness of these techniques is the requirement of considerable time and effort in addition to very restrictive assumptions about the populations being studied.

\subsection{Petersen Method}

Petersen method is the simplest among capture-recapture methods because it is based on a single episode of capturing and a second single episode of recapturing individual units in the population. The procedure is to capture and mark a number of individuals and release them over a short period of time. Then recapture an independent sample of individuals and check for marks. The second sample has to be a random sample for this method to work. In other worlds, all individuals, whether marked or not, must have the same probability of being included in the second sample.

The data obtained in this way include

$\mathrm{M}=$ Number of individuals in the first sample,

$\mathrm{C}=$ Number of individuals in the second sample,

$\mathrm{R}=$ Number of marked individuals in the second sample.

From these three values, we want to obtain an estimate of $\mathrm{N}$ $=$ Number of individuals in the population.

Proportionality argument gives, $\frac{N}{M}=\frac{C}{R}$.

Implying, $\widehat{\mathrm{N}}=\frac{\mathrm{M} * \mathrm{C}}{\mathrm{R}}$.

Where $\widehat{\mathrm{N}}$ is the estimate of population size. This formula is the "Petersen estimate" of population size. This estimate is, however, biased and tends to overestimate the population size. Seber (1982) recommends the estimator

$$
\widehat{N}=\frac{(\mathrm{M}+1)(\mathrm{C}+1)}{(\mathrm{R}+1)}-1 \text {. }
$$

This estimator is unbiased if $\mathrm{M}+\mathrm{C}>\mathrm{N}$ and nearly unbiased if $\mathrm{R}>7$.

\subsection{Lincoln-Petersen Estimator}

The most general approach to estimating the population size is based on the Lincoln-Petersen estimator. The Lincoln-
Petersen estimator is appropriate there are only two sampling occasions. On the first occasion, a sample of individuals is captured, marked, and released in the population. On the second occasion, an independent sample is selected from the population. This sample will have two types of individuals. Individuals that are marked are the individuals that were captured and marked on the first occasion. Individuals that are not marked are the individuals that were not captured on the first occasion. If $\mathrm{N}$ denotes the population size and $\mathrm{n}_{1}$ the sample size on the first occasion, then $\frac{\mathrm{n}_{1}}{\mathrm{~N}}$ is the proportion of marked individuals after the first sampling occasion. It is important to note at this point of time that the numerator $n_{1}$ is known, while the denominator $\mathrm{N}$ is unknown. If $\mathrm{n}_{2}$ denotes the sample size on the second sampling occasion and $\mathrm{m}_{2}$ denotes the number of marked individuals in the second sample, then the proportion of marked individuals in the second sample is given by $\frac{m_{2}}{n_{2}}$. Now, under the assumption that all individuals, whether marked or not, have an equal probability of being selected on the second occasion, the two proportions should be equal. In other words, we must have $\frac{\mathrm{m}_{2}}{\mathrm{n}_{2}}=\frac{\mathrm{n}_{1}}{\mathrm{~N}}$. Since $\mathrm{N}$ is unknown while the other three quantities are known,

We write $\widehat{\mathrm{N}}=\frac{\mathrm{n}_{1} \mathrm{n}_{2}}{\mathrm{~m}_{2}}$.

Note that, on the second sampling occasion, the probability of a marked individual being included in the sample is estimated by $\widehat{\mathrm{p}}=\frac{\mathrm{m}_{2}}{\mathrm{n}_{2}}$ and then the Lincoln-Petersen estimator can be written as $\widehat{\mathrm{N}}=\frac{\mathrm{n}_{1}}{\widehat{\mathrm{p}}}$.

\subsection{Likelihood Approach}

In a two-occasion sampling strategy described earlier, there are only four possibilities regarding an individual in terms of inclusion or non-inclusion in the sample. More specifically, let $\mathrm{n}_{1}$ be the sample size on the first occasion, $\mathrm{n}_{2}$ be the sample size on second occasion, $\mathrm{m}_{2}$ is the number of individuals included in both the samples and $\mathrm{r}$ be the number of individuals included in at least one of the samples. Then, denoting the inclusion probability of an individual in the sample on occasion $\mathrm{i}$ by $\mathrm{p}_{\mathrm{i}}$ (for $\mathrm{i}=1$ and 2 ), the joint probability distribution of $\mathrm{n}_{1}, \mathrm{n}_{2}, \mathrm{~m}_{2}$, and $\mathrm{r}$, is given by

$\mathrm{P}\left[\mathrm{n}_{1}, \quad \mathrm{n}_{2}, \quad \mathrm{~m}_{2} \mid \mathrm{N}, \quad \mathrm{p}_{1}, \quad \mathrm{p}_{2}\right]=\frac{\mathrm{N} !}{\mathrm{m}_{2} !\left(\mathrm{n}_{1}-\mathrm{m}_{2}\right) !\left(\mathrm{n}_{2}-\mathrm{m}_{2}\right) !(\mathrm{N}-\mathrm{r}) !}$ $\times\left(\mathrm{p}_{1} \mathrm{p}_{2}\right)^{\mathrm{m}_{2}}\left[\mathrm{p}_{1}\left(1-\mathrm{p}_{2}\right)\right]^{\left(\mathrm{n}_{1}-\mathrm{m}_{2}\right)} \times\left[\left(1-\mathrm{p}_{1}\right) \mathrm{p}_{2}\right]^{\left(\mathrm{n}_{2}-\mathrm{m}_{2}\right)} \times$ $\left[\left(1-p_{1}\right)\left(1-p_{2}\right)\right]^{(N-r)}$

It should be noted that, $m_{2}+\left(n_{1}-m_{2}\right)+\left(n_{2}-m_{2}\right)=r$.

Since $\mathrm{N}$ is unknown, it is clear that $\mathrm{N}-\mathrm{r}$ is unknown. It is then better to write the conditional joint probability for $\mathrm{n}_{1}$, $\mathrm{n}_{2}$, and $\mathrm{m}_{2}$, given $\mathrm{r}$. This is given by

$$
\begin{aligned}
& P\left[n_{1}, n_{2}, m_{2} \mid r, p_{1}, p_{2}\right]=\frac{r !}{m_{2} !\left(n_{1}-m_{2}\right) !\left(n_{2}-m_{2}\right) !} \times\left[\frac{p_{1} p_{2}}{p^{*}}\right]^{m_{2}} \times \\
& {\left[\frac{p_{1}\left(1-p_{2}\right)}{\mathrm{p}^{*}}\right]^{\left(n_{1}-m_{2}\right)} \times\left[\frac{\left(1-p_{1}\right) p_{2}}{\mathrm{p}^{*}}\right]^{\left(n_{2}-m_{2}\right)}, \text { Where } p^{*}=1-(1-}
\end{aligned}
$$
$\left.\mathrm{p}_{1}\right)\left(1-\mathrm{p}_{2}\right)$.

Maximum likelihood estimates are then easy to obtain before substituting them in place of unknown parameters.

\section{Proposed Method}

This paper proposes a combination of the German tank method and the capture-mark-recapture method as described 


\section{International Journal of Science and Research (IJSR) \\ ISSN (Online): 2319-7064}

Index Copernicus Value (2013): 6.14 | Impact Factor (2015): 6.391

in this section. An assumption for the proposed method to work is that, in the capture-mark-recapture method, the markings should be numbered so that, on the second sampling occasion, the information will not be limited to the number $\mathrm{m}_{2}$ of individuals that got captured on both the occasions. An additional information on their serial numbers $t_{1}, t_{2}, \ldots, t_{m_{2}}$ will also be available, where each of the $t_{i}$ 's can be any positive integer between 1 and $n_{1}$. Using the standard notation, let $\mathrm{t}_{(1)}, \mathrm{t}_{(2)}, \ldots, \mathrm{t}_{\left(\mathrm{m}_{2}\right)}$ be the ordered values of $t_{1}, t_{2}, \ldots, t_{m_{2}}$. Writing $t_{m_{2}}=m$ the German tank estimate is given by $\widehat{\mathrm{n}_{1}}=\left(1+\frac{1}{\mathrm{n}_{2}}\right) \mathrm{m}-1$

It is interesting to note that $\mathrm{n}_{1}$ is already known and it is therefore possible to know whether the sample obtained on the second occasion overestimates or underestimates $\mathrm{n}_{1}$. This information will then be useful in making an appropriate improvement in $\widehat{\mathrm{N}}$ to make it more accurate.

Suppose we take the ratio $\frac{\mathrm{n}_{1}}{\widehat{\mathrm{n}_{1}}}$ as the correctional factor and define $\widehat{N}^{*}=\frac{n_{1}}{\widehat{n_{1}}} \widehat{N}$. The new estimator will reduce the value of $\widehat{\mathrm{N}}$ whenever $\mathrm{n}_{1}<\widehat{\mathrm{n}_{1}}$. On the other hand, the new estimator will enlarge the value of $\widehat{N}$ whenever $n_{1}>\widehat{n_{1}}$. When $\mathrm{n}_{1}<\widehat{\mathrm{n}_{1}}, \widehat{\mathrm{n}_{1}}$ overestimates $\mathrm{n}_{1}$ and so does $\widehat{\mathrm{N}}$. Similarly, when $\mathrm{n}_{1}>\widehat{\mathrm{n}_{1}}, \widehat{\mathrm{n}_{1}}$ underestimates $\mathrm{n}_{1}$ so does $\widehat{\mathrm{N}}$. This is how the correctional factor is justified.

As an aside, it is also interesting to note that one more estimate of the population size $\mathrm{N}$ can be constructed by combining the samples obtained on the two occasions. The number of distinct individuals in the two samples taken together is

$\mathrm{r}=\mathrm{m}_{2}+\left(\mathrm{n}_{1}-\mathrm{m}_{2}\right)+\left(\mathrm{n}_{2}-\mathrm{m}_{2}\right)=\mathrm{n}_{1}+\mathrm{n}_{2}-\mathrm{m}_{2}$

Further, the probability that an individual is included in at least one of the two samples is given by $\mathrm{p}^{*}=1-\left(1-\mathrm{p}_{1}\right)(1$ $\left.-\mathrm{p}_{2}\right)$

Hence, an estimate of $\mathrm{N}$ is given by $\widehat{N}=\frac{r}{p^{*}}=\frac{n_{1}+n_{2}-m_{2}}{1-\left(1-p_{1}\right)\left(1-p_{2}\right)}$.

\section{References}

[1] Amstrup, S. C., McDonald, T. L., and Manly, B. F. J. (2005) Handbook of Capture-Recapture Analysis. Princeton and Oxford: Princeton University Press.

[2] Chen, H. Y. and Robinson, E. H. (2013) A comparison of mark-recapture methods for estimating colony size in the wood ant Formica lugubris. Insect Soc., Vol. 60, pp. $351-359$.

[3] Dorazio, R. M. and Royle, J. A. (2005) Estimating size and composition of biological communities by modelling the occurrence of species. Journal of the American Statistical Association, Vol. 100, pp. 389 398.

[4] Grimm, A., Gruber, B., and Henle, K. (2014) Reliability of Different Mark-Recapture Methods for Population Size Estimation Tested Against Reference Population Sizes Constructed from Field Data. PLOS One, Vol. 9, No. 6, Online Open Access, pp. 1 - 11.
[5] Otis, David L., Burnham, Kenneth P., White, Gary C., and Anderson, David R. (1978) Statistical Inference from Capture Data on Closed Animal Populations. Wildlife Monographs, No. 62, pp. 3-135.

[6] Ruggles, R. and Brodie, H. (1947) An Empirical Approach to Economic Intelligence in World War II. Journal of the American Statistical Association, Vol. 42, No. 237, pp. 72 - 91.

[7] Shen-Ming Lee and Anne Chao (1994). Estimating Population Size via Sample Coverage for Closed Capture-Recapture Models. Biometrics, Vol. 50, No.1, pp. 88-97.

[8] Wagner, T. C., Motzke, I., Furrer, S. C., Brook, B. W., and Gruber, B. (2009) How to monitor elusive lizards: comparison of capture-recapture methods on giant day geckos in the Masoala rainforest exhibit. Zurich Zoo. Ecol. Research, Vol. 24, pp. 345 - 353.

[9] White, G. C. (2008) Closed population estimation models and their extensions in program MARK. Environ. Ecol. Stat., Vol. 15, pp. 89 - 99.

[10] Williams, B. K., Nichols, J. D., and Conroy, M. J. (2002) Analysis and Management of Animal Populations. Academic Press, San Diego. 